\title{
Yield stability and lower susceptibility to abiotic stresses of improved open-pollinated and hybrid maize cultivars
}

\author{
Marcos A. Lana ${ }^{1,2}$ - Frank Eulenstein ${ }^{2} \cdot$ Sandro L. Schlindwein ${ }^{3} \cdot$ Frieder Graef $^{2}$ • \\ Stefan Sieber ${ }^{2} \cdot$ Henrique von Hertwig Bittencourt ${ }^{4}$
}

Accepted: 30 June 2017 / Published online: 24 July 2017

(C) The Author(s) 2017. This article is an open access publication

\begin{abstract}
Maize is one of the world's most important cereals, cultivated in a wide range of environments. Besides the importance of maize and the gains in yield from selection schemes, commercial breeding drastically reduced the number of cultivars of this crop. Current common sense states that hybrids, when compared to open-pollinated cultivars, are a better adaptation strategy to cope with the impacts of climate change. However, the performance and resilience of cultivars with different levels of improvement are still not explored in this context. Four cultivars - a commercial hybrid, one commercially improved open-pollinated, one improved openpollinated derived from participatory breeding, and one from a farmer's selection-were tested using the CERES-Maize crop model. Field experiments conducted in Brazil were used for calibration and evaluation. Synthetic scenarios of climate change resulted from the application of the incremental method on historical series of observations (30 years), with temperature increments ranging from +0.5 up to $+3.0^{\circ} \mathrm{C}$ and precipitation changes from -30 up to $+30 \%$. Planting dates consisted in nine dates (August 1-December 1, each 15 days).
\end{abstract}

Marcos A. Lana

marcos.lana@slu.se; lana@zalf.de

1 Department of Crop Production Ecology, Swedish University of Agricultural Sciences, Ulls väg 16, 75651 Uppsala, Sweden

2 Leibniz Centre for Agricultural Landscape Research (ZALF), Eberswalder Strasse 84, 15374 Müncheberg, Germany

3 Center of Agricultural Sciences, Federal University of Santa Catarina State (CCA/UFSC), Rod. Admar Gonzaga 1346, Florianópolis, SC 88034, Brazil

4 Universidade Federal da Fronteira Sul, Campus Laranjeiras do Sul, BR 158, Km 07, Caixa Postal 106, Laranjeiras do Sul, PR 85301-970, Brazil
Results demonstrate that the model could mimic the phenology and yield of two improved open-pollinated cultivars (MPA01 and Fortuna) and the hybrid (AS1548). One openpollinated cultivar could not be validated due to its high phenotypic variability. Yield response surfaces showed distinct impacts among cultivars, with improved open-pollinated cultivar MPA01 having a higher yield stability when compared to the hybrid. Early planting dates produced lower yields with higher risk of crop failure for all cultivars. Late planting dates produced higher yields with higher failure risk. Considering risk and yield, the best planting window for all cultivars and scenarios is between September and October. Our results demonstrate, for the first time, that improved open-pollinated cultivars are equivalent or more resilient than hybrids to yield changes under different scenarios of abiotic stresses.

Keywords Crop model $\cdot$ Corn · DSSAT · Local cultivars · Yield $\cdot$ Model calibration $\cdot$ Climate change $\cdot$ Adaptation strategy $\cdot$ Zea mays

\section{Introduction}

Maize (Zea mays L.) is one of the world's most important crops for food security, cultivated for human and animal consumption, but in recent years is increasingly playing an important role as biofuel source. The intense selection and improvement of the species generated a high number of cultivars adapted to a wide range of climatic conditions from temperate to tropic climates, although resulting at the same time in a drastic reduction of genetic diversity, posing a great risk in terms of susceptibility to diseases, pests, and abiotic stresses such as drought and heat stresses (Fig. 1). Nevertheless, in many parts of the world, farmers still keep these openpollinated cultivars and also generating new ones (Kuhnen 
Fig. 1 Effect of different planting dates of the same maize cultivar (MPA01) in the same location (Guaraciaba, Brazil). On the left, maize was planted on August 1; on the right, planting date was October 1. On the left, the earlyseason low temperatures delayed the development of maize, and anthesis took place during a dry spell with high temperatures (late November), preventing silk elongation and appropriate pollination. The damage, in this case, could not be reduced by the following precipitation events. For the late planting date, the dry spell was not deleterious as it occurred during a stage where the water demand of the plants is low
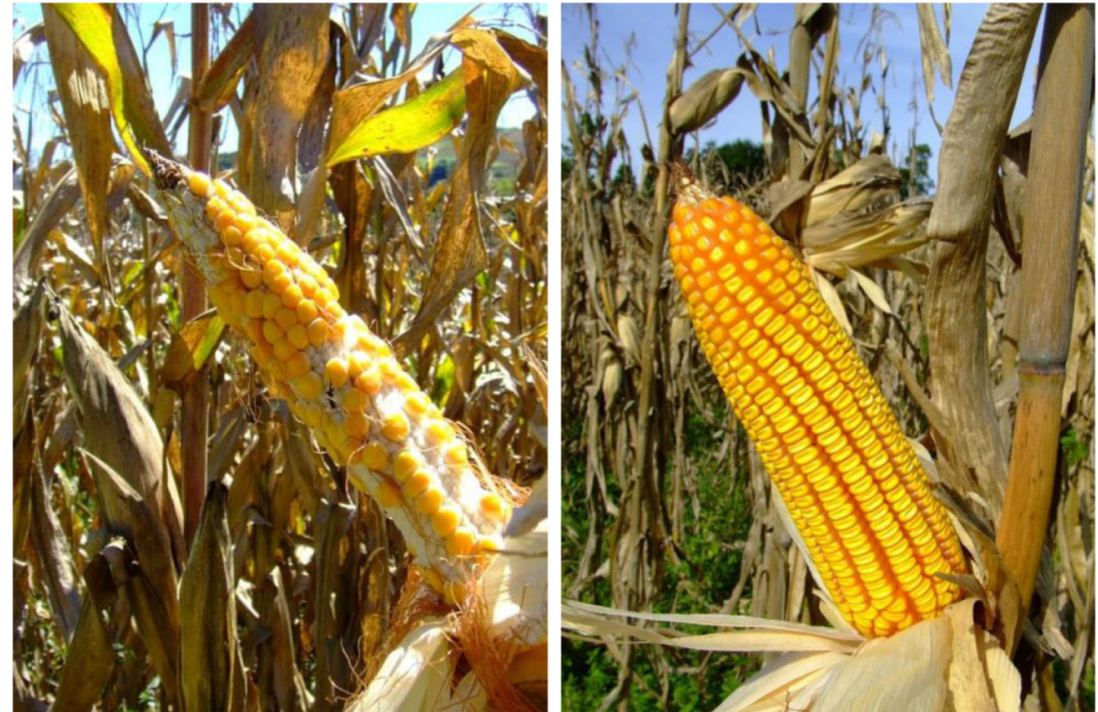

et al. 2010), even though progressively, these open-pollinated cultivars have been replaced by modern cultivars. Thereby, a valuable source of germplasm for meeting the future needs of sustainable agriculture in the context of climate change is lost. The open-pollinated cultivars, although usually yielding less than the modern hybrids (Kutka 2011), are better suited for medium- to low-input farming systems. The highest genetic variability brings more adaptability and rusticity, besides the fact that the farmer can produce his own seeds for the next season (Bellon et al. 2006), reducing significantly the production costs. These characteristics make the improved openpollinated cultivars an interesting option especially for small farms like the ones located in Southern Brazil. The region was responsible for 39\% of Brazil's maize production in 2011 (IBGE 2015) and is characterized by small to medium farms, where $65 \%$ of the rural establishments have less than 20 ha and the vast majority $(84 \%)$ are family owned and operated. Information about the use of specific open-pollinated cultivars is not available in Brazil, but data from seed industry (ABRASEM 2006) indicates that $15 \%$ of the Brazilian maize producers use non-commercial seeds (in other terms, own production or from farmer to farmer seed exchange initiatives), and about $12 \%$ of the cultivars available in the market are improved open-pollinated cultivars. In the Western region of the Santa Catarina State, Southern Brazil, maize cultivars with special agronomic and nutritional traits have been developed and cultivated by small farmers over the last decades (including the cultivars MPA01 and Ivanir). In the same region, $41 \%$ of the small rural establishments utilize openpollinated cultivars (Canci et al. 2004), many under agroecological management. Considerable part of the improved openpollinated cultivars, in opposition to the traditional landraces, is breed using participatory methods, which, in addition to the advantage of being adapted to the local environment, are adopted much earlier than cultivars breed in conventional systems (Joshi et al. 2014), so as having a much lower cost. Besides assuming the relative small share in Brazil's total production, they play a considerable role as source of genetic diversity, cultural heritage, and suitable option for marginal areas, which are usually more susceptible to abiotic stresses.

Climate change is of global concern, and regardless of all the initiatives and scientific advances to understand and forecast changes, the determination of future climate is still a very hard task. The high level of complexity and the nature of climatic interactions are a challenge to forecasting, although there are scenarios that point to possible directions of change.

The impact of climate change on agricultural production is actually the core issue of several investigations. The accumulation of carbon dioxide $\left(\mathrm{CO}_{2}\right)$ and other greenhouse gases in the atmosphere at unprecedented rates will cause increased radiative forcing. The continued emissions of greenhouse gases will also promote an increase in annual temperatures by 2.6 to $4.8{ }^{\circ} \mathrm{C}$ in important crop-growing regions of the world by 2081 to 2100, according to the Representative Concentration Pathway 8.5 of the Intergovernmental Panel on Climate Change (IPCC 2014). Growing season temperatures are expected to change more than the annual averages, with reduced precipitation expected to accompany higher temperatures in some regions. Additionally, heat waves are expected to increase in frequency, intensity, and duration. End-of-century growing season temperatures in the tropics and subtropics may exceed even the most extreme seasonal temperatures measured to date. Not considering all the inherent variability of crop production factors, all climate changes described above can lead to modifications of maize yields, posing a threat to agricultural systems that will affect the whole maize production and consumption chain, impacting especially agroecosystems and populations with low availability of or access to financial and natural resources. On top of that, in recent years, there has been a frightening decline in global 
grain stocks (Hall and Richards 2013) which, together with adverse weather conditions in some regions, can result in spikes in food prices.

Crop models can be a useful tool to assess the influence of climatic and other environmental or management factors on crop development and yield (Reidsma et al. 2010). The Decision Support System for Agrotechnology Transfer (DSSAT) v. 4.5 contains the Crop System Model CERESMaize model (Jones et al. 2003) and can help to (a) determine best planting dates, (b) define fertilization timing and amount, (c) support precision agriculture, and (d) detect/investigate potential impacts of climate change on agriculture. In the embedded CERES-Maize model, the development and growth of the crop are simulated on a daily basis from the planting until the physiological maturity. The model calculations are based on environmental and physiological processes that control the phenology and dry matter accumulation in the different organs of the plant. The DSSAT also has other embedded models that can simulate the flow of nutrients and water balance in the soil. The minimum data set necessary to run DSSAT consists of daily weather data of maximum (Tmax) and minimum (Tmin) temperature, rainfall and solar radiation, soil chemical and physical parameters for each layer of the soil profile, genetic coefficients for each cultivar with information about development and biomass accumulation, and management information, such as soil preparation, planting dates, plant density, fertilization amounts and timing, or other agricultural practices. Regarding crop parameters, the introduction of a new cultivar in a process-based crop simulation model requires the estimation of cultivar coefficients that define its growth and development characteristics (Bannayan and Hoogenboom 2009). Experimental data like plant phenology, biomass partitioning, and other morphological components like leaf area index are mandatory to calibrate the genetic coefficients and to test the overall reliability of the model simulation. Information about soil available water and nutrients is also required.

The objectives of this study are (1) carry out yield response surfaces for different maize cultivars and planting dates under climatic scenarios and (2) establish the effect of adaptation strategies (cultivar and planting date) against climate change. In order to accomplish that, the characterization of genetic coefficients of three open-pollinated maize cultivars and one commercial maize hybrid for CERES-Maize was done, and DSSAT was calibrated and validated for the study region.

\section{Materials and methods}

\subsection{Field experiments}

The field experiments were set up at a farm in Guaraciaba (Lat. $-26.574013^{\circ}$, Long. $-53.578364^{\circ}$ ), Santa Catarina
State, Brazil, during 2010 and 2011. The aim was to carry out the field experiments together with the farmer in a realistic situation where maize cultivars are grown, but maintaining the scientific rigor. The climate of the region is classified as Cfa according to Köppen-Geiger (Peel et al. 2007): humid subtropical climate characterized by hot, humid summers and generally mild to cold winters. Climate data of the region is shown by Fig. 2.

Three improved open-pollinated maize cultivars (MPA01, Ivanir, and EPAGRI Fortuna) and one hybrid (AS 1548) were used. The cultivar MPA01 development started in 1999 by an intercross of 25 cultivars (commercial hybrids, landraces, and local cultivars) using recurrent convergent-divergent selection in a participatory process with small farmers (Kist et al. 2010); the cultivar Ivanir is the result of the farmer's mass selection from an uncontrolled mixture of cultivars from the previous season; the cultivar Fortuna is an open-pollinated cultivar developed from six different hybrids by the Agricultural Research and Rural Extension Enterprise of Santa Catarina State (EPAGRI) and is adapted for low to medium input farming systems. The AS1548 is a commercial short-season simple hybrid from the AGROESTE Company with high performance. With exception of the Ivanir cultivar, all the cultivars
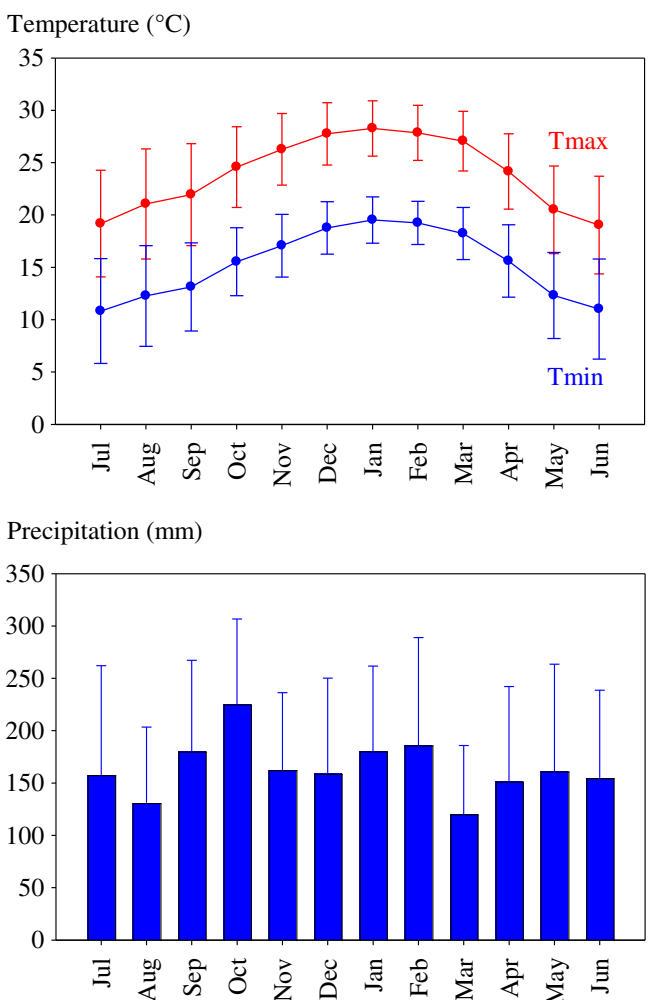

Fig. 2 Monthly averages of maximum and minimum temperatures and precipitation (based on daily observations of 1982 to 2012) for the study region in Brazil. This data set was used as base for the synthetic weather scenarios. Bars represent the standard deviation (source: CIRAMEPAGRI) 
present features that are considered advanced genetic gains derived from breeding, such as stay-green (Duvick 2005).

The experiments consisted in the four maize cultivars planted at three different dates during the crop season (October 26, November 16, and December 6). All experiments had a randomized complete block design with four replications, performing a total of 48 plots. Each plot was $18 \mathrm{~m}$ in length with four rows spaced at $0.75 \mathrm{~m}$, with a final plant population of 65,000 plants per hectare. The fertilization consisted in the equivalent of $9 \mathrm{tha}^{-1}$ of turkey manure $(1.5 \%$ of N, $2.3 \%$ of $\mathrm{P}$, and $2.5 \%$ of $\mathrm{K}$ ) banded beneath surface and applied prior to the planting.

\subsubsection{Weather and soil data}

Three automatic weather stations were placed within the experimental field to record precipitation and maximum and minimum temperatures. Solar radiation data was obtained from a nearby station located in Chapecó, Santa Catarina State.

The soil of the experiment is a Typic Hapludoll. Physical and chemical parameters were determined in samples collected at $10-\mathrm{cm}$-depth intervals prior to the experiment. To obtain the gravimetric soil water content during the field experiment, samples were collect at depths of the 0-20, 20-40,40-60, and $60-100 \mathrm{~cm}$ at planting date and at each biomass sample (V6, VT, R1, R4, and R6 stages) (Ritchie et al. 1998).

\subsubsection{Plant measurements}

The plant phenology measurements consisted in recording of the dates of the emergence, V4, V6, V8, V10, VT, R1, R3, R4, and R6 stages. Plant biomass was collected at stages V6, VT, R1, R4, and R6 using destructive methods to sample leaf area and partitioning of above ground biomass of all plants from one linear meter from the two central rows. In the central rows, one linear meter was left to act as a border between each sample site. The final harvest from field experiments consisted in harvesting all last $8 \mathrm{~m}$ (respecting a 1-meter border at the end of the rows). All weights - leaves, stem, husk, ear, and grains - were obtained by drying the biomass until constant weight at $70{ }^{\circ} \mathrm{C}$.

\subsection{Calculation of genetic coefficients and calibration}

Once the field experiment was finished, all the data collected (weather, soil, biomass, and phenology parameters) was included in the Cropping System Model (CSM)-CERES-Maize model to start the calibration. In order to estimate the genetic parameters of the maize cultivars, a Bayesian method was employed (Boote 1999). This method uses Monte Carlo sampling from prior distributions of the coefficients and a Gaussian likelihood function to choose the ones that best match the observed values. The advantage of this approach is to combine information of different observations to estimate the probability of distribution of parameter values and model predictions. To achieve this task, a generalized likelihood uncertainty estimation (GLUE) methodology was employed. The process was initially run only for developmental parameters to correctly simulate the plant phenology $(\mathrm{P} 1$, thermal time from seedling emergence to the end of the juvenile phase; $\mathrm{P} 2$, extent to which development is delayed for each hour increase in photoperiod above the longest photoperiod at which development proceeds at a maximum rate; $\mathrm{P} 5$, thermal time from silking to physiological maturity; and PHINT, the interval in thermal time between successive leaf tip appearances), adjusted, and then run for growth coefficients (G2, maximum number of kernels per plant and G3, kernel-filling rate), with 30,000 runs for each step. Each run generated indexes to compare the simulated with the observed values. At the end of the process, the coefficients with higher probability of matching the observed values from filed experiment were selected.

\subsection{Validation of the genetic coefficients and the CSM-CERES-Maize}

In order to analyze the model's performance for each cultivar, available data sets of field data (soil, weather, management, phenology, and yields) from other field experiments done in different regions of Santa Catarina State (for MPA01: number of experimental data $(n)=10$, Fortuna: $n=7$; AS1548: $n=6$, Ivanir: $n=3$ ) were included in DSSAT for validation runs. The controlled experiments that generated the data sets consisted in trials done in Santa Catarina State by the State's Agricultural Service (EPAGRI) and universities with the aim of providing advice to farmers regarding the most adequate cultivars and agronomic management. The basic data set consisted by agronomic management, germination, anthesis, maturity date, and yield, followed by detailed information of phenology and morphology. The simulated yields, anthesis, and maturity dates (using the generated genetic coefficients) were then compared against observed values following the recommendations of Wallach et al. (2014). The normalized root-mean-square error (RMSE) and the coefficient of residual mass (CRM) were calculated with the following equations:

$$
\begin{aligned}
& \text { RMSE }=\sqrt{\frac{\sum_{i=1}^{n}\left(P_{i}-O_{i}\right)^{2}}{n}} \times \frac{100}{M} \\
& C R M=\frac{\sum_{i=1}^{n} O_{i}-\sum_{i=1}^{n} P_{i}}{\sum_{i=1}^{n} O_{i}}
\end{aligned}
$$

where $n$ is the number of observations, $P_{i}$ the predicted value, $O_{i}$ the observed value, $M$ the mean of the observed variable, 
$P^{\prime}{ }_{i}=P_{i}-M$ and $O_{i}^{\prime}=O_{i}-M$.

The normalized RMSE (Eq. (1)) gives a measure (in \%) of the relative difference of simulated versus observed data (Loague et al. 1991). The simulation is considered excellent with a normalized RMSE lower than $10 \%$, good between 10 and $20 \%$, fair from 20 to $30 \%$, and poor if the normalized RMSE is greater than $30 \%$ (Jamieson et al. 2010). The CRM (Eq. (2)) is a measure of the tendency of the model to overestimate or underestimate the measurements: if negative, the model tends to overestimate the measurements (Homaee et al. 2002). If all simulated and observed values are the same, then RMSE and CRM values should be equal to zero.

\subsection{Scenario construction}

After calibrating and validating the genetic parameters and the model itself, synthetic weather scenarios were constructed using the incremental method. In this approach, the climate parameters (daily values of Tmax, Tmin, and precipitation) are changed by realistic but arbitrary amounts. For example, to create a $+1{ }^{\circ} \mathrm{C}$ incremental scenario, the daily $\operatorname{Tmax}$ and $\mathrm{Tmin}\left(\right.$ in ${ }^{\circ} \mathrm{C}$ ) are increased by one unit along the whole historical series; to create an incremental scenario of $-10 \%$ of rainfall, values of precipitation events are multiplied by 0.9 . The incremental scenarios are commonly applied to study the sensitivity of an exposure unit to a wide range of variations in climate and to construct impact response surfaces over multivariate climate space. For this paper, the observed weather data from Chapecó agrometeorological weather station (Lat. -27.0852 , Long. $-52.6356,677 \mathrm{~m}$ above sea level) form the baseline data (daily observations from 01.01.1982 to 01.05.2012, 30 planting seasons). Then, Tmax and Tmin were increased by $0.5{ }^{\circ} \mathrm{C}$ until a total increment of $+3{ }^{\circ} \mathrm{C}$ (seven levels); precipitation was changed at $10 \%$ intervals, from -30 to $+30 \%$ ( 7 levels), all together summarizing 49 combinations or scenarios. Solar radiation was not changed because the reduction of direct radiation (due to clouds in the case of scenarios with positive increments of precipitation) is usually accompanied by an increase in diffuse radiation, which is even more effective for photosynthesis than the direct radiation, and therefore radiation is not a significant limiting factor in the study region. The levels of $\mathrm{CO}_{2}$ were adjusted to $491 \mathrm{ppm}$ (parts per million), a concentration expected for the 2040 decade according to the ISAM modelscenario A1B (Cubasch et al. 2001). The effect of $\mathrm{CO}_{2}$ increment will not be discussed, as the differences between the simulations with current level (395 ppm) and projected level for 2040 (491 ppm) did not produce consistent changes, increasing yields by 0 to $4 \%$, in agreement with recent studies (Markelz et al. 2011).

\subsection{Yield simulations}

The model was run for 30 cropping seasons using the distinct synthetic weather scenarios in combination with nine different planting dates within the recommended maize planting window for the study region (01.08 until 01.12 , each 15 days) to reduce intra-annual variation. The model employed the same management (fertilization, no irrigation) and environmental conditions (soil) used for model calibration. The yield reference for each planting date was calculated using observed data weather (1982-2012). For each scenario, the median $(\varrho)$ of all planting dates in the 30 years was computed as yield of the given scenario and then converted to a percentage of yield departure from the yield reference $\left(Y_{\mathrm{REF}}\right)$ as shown in Eq. (3):

$$
Y_{\mathrm{REF}}=\frac{\frac{\sum_{i=1}^{n} \varrho P_{i}}{n}-\frac{\sum_{i=1}^{n} \varrho O_{i}}{n}}{\frac{\sum_{i=1}^{n} \varrho O_{i}}{n}} \times 100
$$

where $\varrho P_{i}$ is the median of the predicted yield from all planting dates in the same year, $\mathrm{\varrho} O O_{i}$ the median yield simulated with past conditions (1982-2012) of all planting dates in the same year, and $n$ the number of years. For analyzing the effect of planting dates, simple medians of each scenario and planting date were taken, and the probability of crop failure occurrence was calculated. Crop failure was characterized as any yield under the half of the lower quartile (25th percentile) of the given planting date and scenario.

\section{Results and discussion}

\subsection{Calculation of genetic coefficients and model validation}

The calculation of crop parameters is a very important step to ensure the simulation accuracy, and crop model parameters can only be derived from field experiments where growth and development processes have been measured. In addition, models are also frequently not subjected to calibration, but crop parameters are obtained from the literature assuming that they can be uniformly applied over large regions. The lack of reliable field data and the use of inappropriate crop parameters have consequences that affect the accuracy of the simulations. For this work, the values obtained from the direct field measurements and processed using GLUE generated the genetic coefficients shown by Table 1 . The advantage of this procedure was that it used values from field observations - which represent the population variability, especially in populations that have a natural variability such as open-pollinated crops- 
Table 1 Cultivar coefficients of four maize cultivars calculated by GLUE using field measurements (on top), followed by model validation outcomes for phenology (anthesis and physiological maturity) and yield

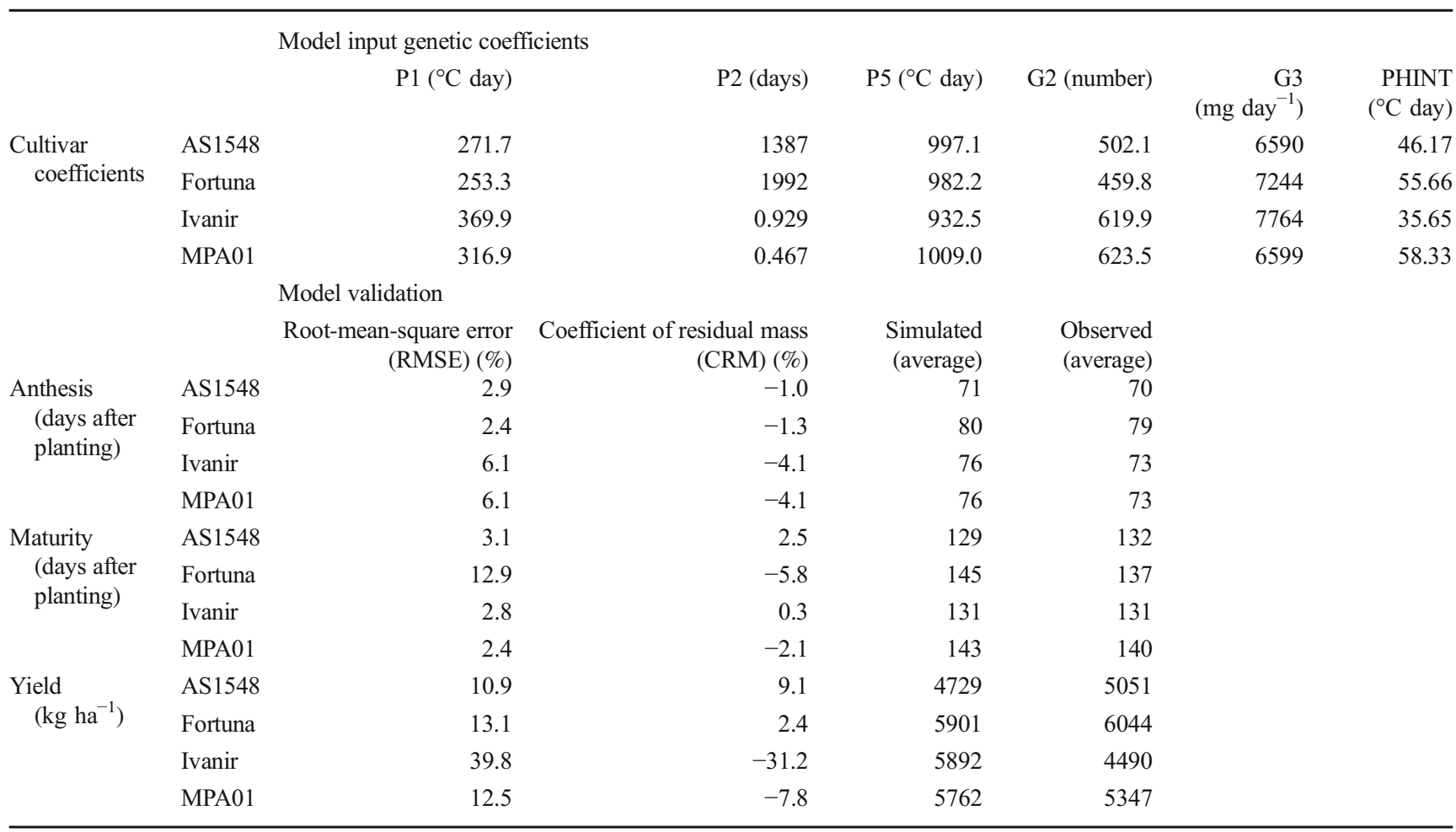

$P 1$ thermal time from seedling emergence to the end of the juvenile phase (degree days above the base temperature of $8{ }^{\circ} \mathrm{C}$ ) during which the plant is not responsive to photoperiod, $P 2$ extent to which development is delayed for each hour increase in photoperiod above the longest photoperiod at which development proceeds at a maximum rate $(12.5 \mathrm{~h}), P 5$ thermal time from silking to physiological maturity (above a base temperature of $8{ }^{\circ} \mathrm{C}$ ), $G 2$ maximum possible number of kernels per plant, $G 3$ kernel filling rate during the linear grain-filling stage under optimum conditions (mg day ${ }^{-1}$ ), $P H I N T$ phyllochron interval $=$ thermal time (degree days) between leaf tip appearances

as a range of values for the different parameters. This procedure helped the modeling process by adjusting parameters to minimize the differences between calculated values and independent observations while maintaining crop parameter values within a realistic range and reflecting the variability that exists in nature (as genotypic variability).

The cultivars Fortuna and AS1548 required the lowest thermal time (P1) from seedling to the end of the juvenile phase, indicating a distinctive characteristic of short-season maize, while the cultivars MPA01 and Ivanir required a higher thermal sum during this phase. A remarkable difference in the parameter P2 was observed among the cultivars, evidencing the effect of the photoperiod on plant development. The thermal time from silking to maturity (P5) had little difference among the cultivars. The maximum number of grains per plant (G2) was similar between MPA01 and Ivanir (623 and 619 grains per plant, respectively), and the cultivar Fortuna had the lowest number of grains per plant. The grain-filling rate ranged from 6.59 to $7.76 \mathrm{mg} \mathrm{day}{ }^{-1}$, with AS1548 and MPA01 having the lowest rate. The phyllochron interval was very short for Ivanir $\left(35.65{ }^{\circ} \mathrm{C}\right)$, whereas for MPA01 was of $58.33{ }^{\circ} \mathrm{C}$. These results reinforce the effect of cultivar traits in phenology and biomass production and are even more evident when comparing the coefficients from other cultivars such as the ones described by Padilla and Otegui (2005).

After calibration of genetic coefficients, simulations were run using environmental conditions (soil, weather) and agronomic management (planting date, fertilization, plant population, soil management) from other independent experiments conducted (using the same cultivars) in Santa Catarina State, Brazil, in order to contrast predicted against measured values for each cultivar (Table 1).

Concerning the simulation of anthesis date (expressed in the model as days from planting to anthesis), all cultivars had excellent values of RMSE; the CRM values had a slight overestimation of the anthesis day. Concerning the simulation of maturity date (expressed in the model as days from planting to physiological maturity), all cultivars, except Fortuna, had excellent RMSE values and low values of CRM. One of the possible reasons is that this cultivar, as an open-pollinated product of a mass selection, still has a certain genetic instability. As this cultivar is not established, yield and phenology can differ from seed lot to seed lot, causing a reduction in its performance predictability. For yield, the RMSE of all 
cultivars except Ivanir was considered good (Loague et al. 1991), with values ranging from 10.9 to $13.1 \%$, indicating low relative difference between simulated and observed data, so as with CRM. As the Ivanir cultivar is the result of a broad seed lot mass selection done by the farmer, it tends to possess significant phenotypic variability (Mercer and Perales 2010). This high level of heterogeneity leads to unpredictability of characters, especially yield (RMSE $=39.8 \%$ ), which is a polygenic characteristic. For this reason, it was not possible to evaluate the performance or yield stability of this cultivar. In addition, the lower availability of data sets for this cultivar $(n=3)$ also contributes to the poor model validation. Similarly, the lack of more independent data about this cultivar prevented the understanding if the variability is intrinsic to the population or caused by the seed lot used for calibration. Eventually, a larger field data-set for calibration and evaluation could overcome this problem and endorse further analysis of yield and yield stability with this cultivar.

The abovementioned analysis endorsed the model capability of adequate reproduction of phenology and growth of the hybrid AS1548 and the two open-pollinated cultivars (MPA01 and Fortuna) in different environments and seasons, but not Ivanir. The yields simulated using the observed weather (baseline), when contrasted with survey data obtained from the 2000-2011 cropping seasons, also indicate that simulated yields (Table 1) are within the range of observed yields for the west part of the Santa Catarina State (3689 to $6275 \mathrm{~kg} \mathrm{ha}^{-1}$, with an average of $4693 \mathrm{~kg} \mathrm{ha}^{-1}$ ). Finally, it is important to remark that the crop parameters were calculated and validated for the studied region, and any attempt to use them in other environments must ideally be preceded by an evaluation using local data.

\subsection{Yield simulation for planting dates}

Simulations to observe the effect of different combinations of temperature and precipitation increments were done for two open-pollinated cultivars and the hybrid cultivar in nine different planting dates. The open-pollinated cultivar Ivanir was not used due to the lack of confidence shown by the model validation (Table 1). Regarding different planting dates, the scenarios had impacts on yields. The main factor that affected the yield was precipitation, which severely reduces yields or induces "crop failure" by not providing enough water for germination, development, or grain filling. In all scenarios, the very earlier planting dates (August 1 and 15) had the lowest yields and also the highest crop failure probability. The main causes are late frost risk and hydrological stress during development and grain-filling stage (Fig. 1). The relationship between maize yield and soil water at sowing, as observed by Zhang et al. (2014) in the Chinese Loess Plateau, highlighted the importance of water supply for guaranteeing crop growth at early stages. For the current conditions (named "current"), so as for the scenarios, the safest planting date is between earlier September and October (Fig. 3), when temperatures are not so high and precipitation reaches adequate levels for crop establishment, as well as during development and grain filling. On the other hand, crops planted in November can
Fig. 3 Maize yields (left) and probability of crop failure (right) based on the median of $30 \mathrm{crop}$ seasons of three different cultivars (AS1548, Fortuna, and MPA01) in nine different planting dates in current climatic conditions and in four selected incremental scenarios with increment of +1 and $+3{ }^{\circ} \mathrm{C}$ in maximum and minimum temperatures $(\mathrm{T})$ and -30 or $+30 \%$ in precipitation $(\mathrm{P})$ amount
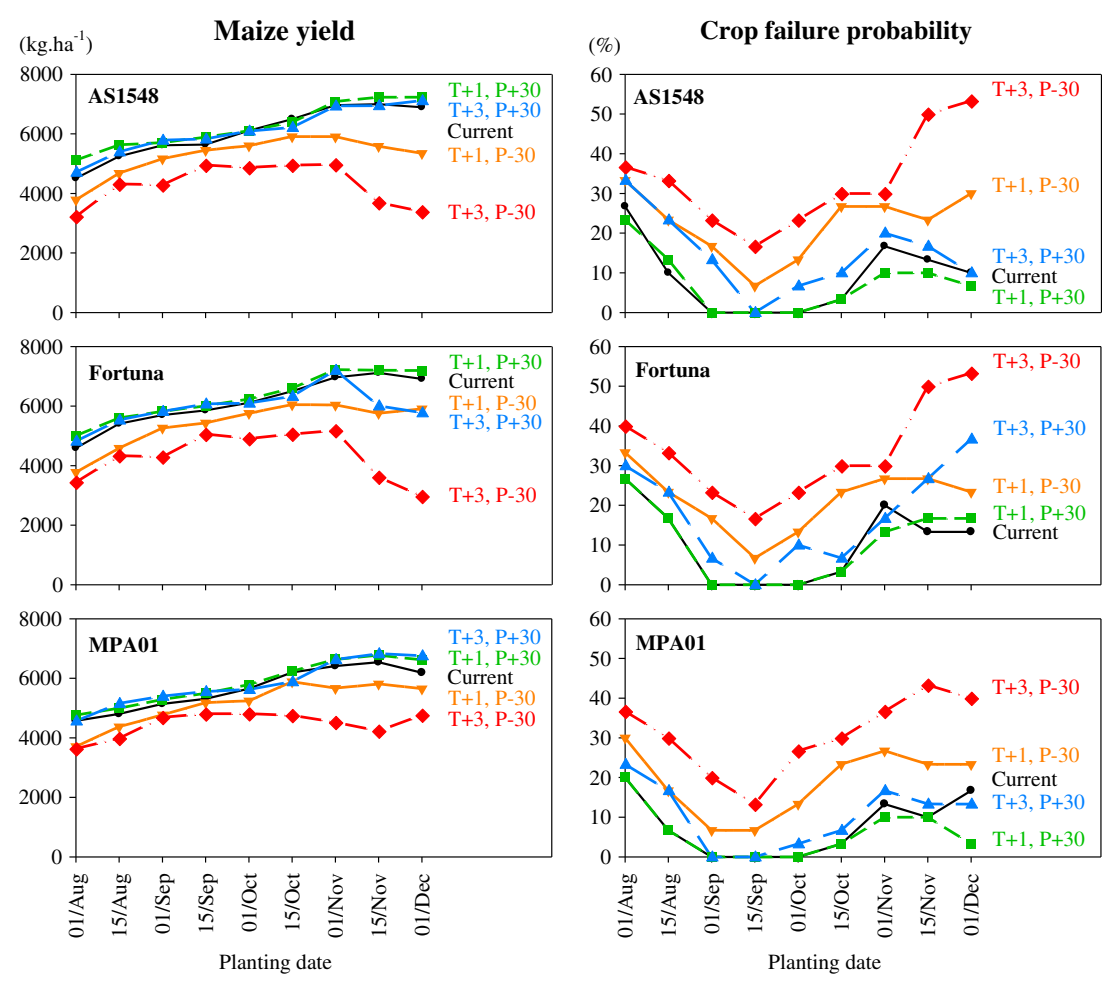
have higher yields (AS1548, Fortuna, and MPA01, with 6962, 6964 , and $6412 \mathrm{~kg} \mathrm{ha}^{-1}$, respectively), but again with higher risk of crop failure. Late planting, in this situation, can result in a significant deterioration of environmental conditions (temperature, radiation, and water availability) during grain filling. This rise in the yield of the combination "last planting date" along with increasing precipitation scenarios can be attributed to the increment of water availability during the grain-filling stage, which for this planting date occurs in March, usually the driest month (Fig. 2).

The impact of temperature increases on crop failure was not so pronounced as the impact of precipitation, but is not insignificant. Considering the most extreme scenario $\left(+3{ }^{\circ} \mathrm{C}\right.$ combined with $-30 \%$ precipitation), the failure probability ranged from 13, 17, and 17\% (respectively for MPA01, AS1548, and Fortuna planted in September 15) to 53\% (AS1548 and Fortuna, planted in December 1). Scenarios with an increment in temperature of $+3{ }^{\circ} \mathrm{C}$ combined with $+30 \%$ precipitation resulted in a probability of failure lower than the one observed in scenario $+1{ }^{\circ} \mathrm{C}$ and $-30 \%$ in precipitation for all cultivars and planting dates, except for one planting date for the Fortuna cultivar (December 1). Temperature influences the majority of processes involved in living organisms, and regarding plant growth and development, temperature plays an important role in all physiological processes, in evapotranspiration, and also determines the start, the length, and the end of phenophases. Higher temperatures can accelerate the crop development in such a way that plants do not have time to complete their vegetative growth adequately and accumulate biomass before entering the reproductive stage, as expected when temperate cultivars (usually with lower thermal sum requirements) are cultivated in tropical regions. This faster development can also cause situations in which sensible development stages of the crop occur during adverse climatic conditions, such as a drought spell (Fig. 1) or early frost. The results also indicate that the effect of temperature gains importance as the planting dates advance, since it accelerates the plant development in such a way that the grain-filling stage might occur in a period of reduced precipitation and relatively high temperature (Fig. 2, March). When comparing the response to changes in temperatures, it is possible to observe that all tested cultivars follow a similar response trend. The magnitude of the probability of failure is similar for AS1584 and Fortuna, whereas lower for MPA01 (Fig. 3).

\subsection{Yield forecast for different incremental scenarios}

Yield stability is an emergent property that depends on many factors, ranging from environment characteristics to crop and cultivar parameters. In this study, as all cultivars were submitted to the same environment and agronomic management, it can be assumed that cultivar specific parameters will shape crop responses.
Figure 4 shows response surfaces of the percentage of yield departure from the yield reference (Yref) of each cultivar, with isolines dividing the changes in yield. The response surfaces show remarkable differences among cultivars. The openpollinated cultivar MPA01 had the highest yield stability in different scenarios of temperature and precipitation, maintaining the same yields (Fig. 3) even with reductions in precipitation amount $(10 \%)$ or increment in temperature $\left(+1{ }^{\circ} \mathrm{C}\right)$. This effect is evidenced by the large area occupied by the "nochange" area. The almost vertical pattern of the contour lines in Fig. 4 also suggests that for this cultivar, changes in precipitation are more impacting than temperature, even showing a $5 \%$ yield increase with $20 \%$ more precipitation. This higher stability can be attributed to higher thermal sum required for this cultivar to complete its cycle, which allows more time to develop and eventually recover from short drought periods (P1 and P5 parameters). The other open-pollinated cultivar Fortuna had a lower stability across the different scenarios when compared with MPA01, responding almost equally to temperature and precipitation: the proximity of the contour lines indicates a higher responsiveness, but only above $+1{ }^{\circ} \mathrm{C}$; under this threshold, the yields are almost not influenced by temperature. When temperatures increments are above $+2{ }^{\circ} \mathrm{C}$ and combined with reduction in precipitation, yields drop $20 \%$ or more due to faster development and increase in water demand. The hybrid AS1548 had the lowest yield resilience, maintaining its actual yields only in situations of temperature increment of $+0.5^{\circ} \mathrm{C}$. Precipitation increments are not very effective to increase the yield for this hybrid when compared to the open-pollinated cultivars. The almost diagonal inclination of the contour lines suggests that this hybrid is more responsive to any changes of temperature and precipitation combined than the other two cultivars. The relative correspondence between AS1548 and Fortuna performance could be explained by the similarity of their genetic coefficients (Table 1). Despite being an established open-pollinated cultivar derived from recurrent selection, Fortuna was originally obtained from crossings that also included hybrids. Probably because of that, this cultivar reached the highest yields under current conditions (Table 1), corroborating the statement of Kutka (2011), for whom yield of openpollinated cultivars can be improved to be competitive with hybrids, especially in tropical regions. Regarding the scenarios, Fortuna and AS1548 had the highest yields. However, when compared to MPA01, both cultivars had higher risk of losses under unfavorable conditions (Figs. 3 and 4).

In crop simulation studies, differences among cultivars rely on the crop parameters used for model parameterization, including phenological events (germination, anthesis, and maturity), biomass partitioning (in stems, leaves, cobs, and grains), and morphological aspects (leaf area index and number of grains). The higher stability of MPA01, in this case, can be attributed partially, but not solely, to the P1 parameter: it 
Fig. 4 Response surfaces showing yield change (in \%) from the reference $\phi$ (1982-2012 yields) using different maize cultivars in scenarios with increments of precipitation and temperature. Cultivars: a MPA01 $\left(\phi, 5647 \mathrm{~kg} \mathrm{ha}^{-1}\right)$, b Fortuna ( $\phi$, $6051 \mathrm{~kg} \mathrm{ha}^{-1}$ ), and $\mathbf{c}$ AS1548 ( $\phi$, $6127 \mathrm{~kg} \mathrm{ha}^{-1}$ ). The closer proximity of isolines indicates a faster reaction to temperature and/ or precipitation changes
MPA01

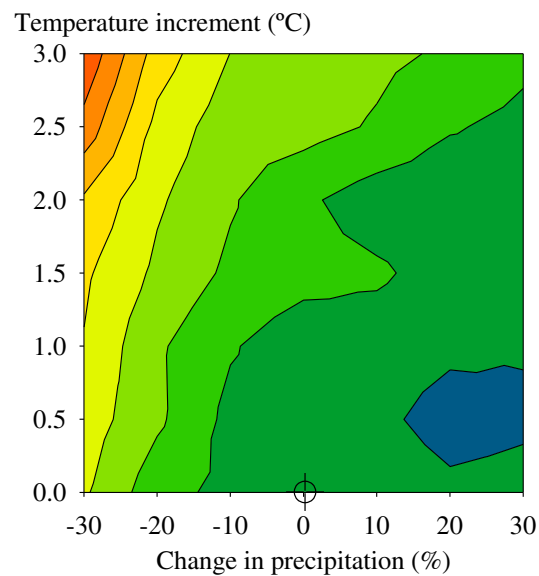

FORTUNA

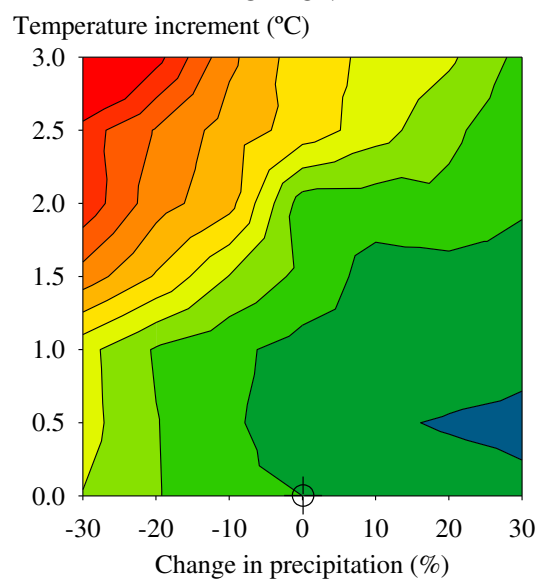

AS1548

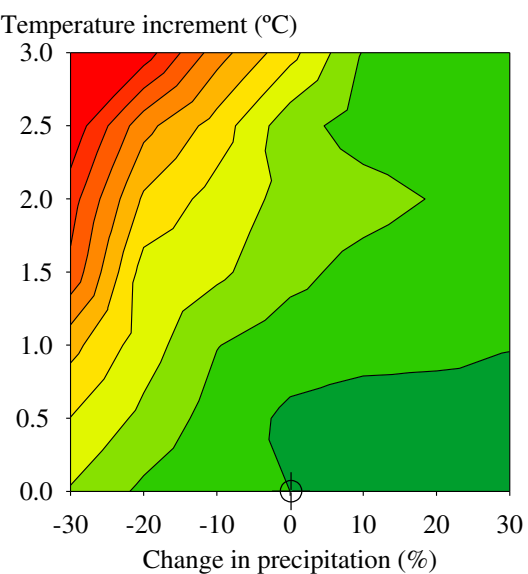

Yield change

$-20 \%$

$-15 \%$

$-10 \%$

$-5 \%$

no change

$+5 \%$ represents the thermal time from seedling emergence to the end of the juvenile phase, indicating that among the three selected cultivars, it is the one that requires the highest thermal accumulation - or time - to trigger the reproductive stadium. This longer vegetative period generally means higher leaf area, which in turn allows for not only higher dry matter fixation during grain-filling stage - but also increasing the evapotranspiration and risk of water stress. This also means that if a stress occurs during the vegetative period, the plant has still a possibility to recover from it. As the MPA01 is a locally developed cultivar, it can be assumed that the set of characteristics - which suit well to the studied region - was indirectly and eventually unconsciously selected by the farmers during the participatory breeding process, as explained by Newton et al. (2010). This indirect selection is also presented in conventional breeding programs, since phenology is usually not a target in breeding programs. It is also important to emphasize that under other circumstances - in a region with a reduced rainy season, for example - short to very short cultivars might have the advantage of reaching maturity before the end of the rainy season, while a longer maturity cultivar could be negatively impacted. This emphasizes the importance of a synchronicity between phenology and weather pattern during the cropping season. Although there are differences in phenological parameters among the tested cultivars, they can be considered to belong to the same maturity group, as the observed interval of physiological maturity from the first (AS5814) to the last cultivar (MPA01) was not higher than 8 days (Table 1). As the crop model calculates simultaneously the effect of different parameters on development and ontogenesis of the crop, in a complex interplay, the identification of a single characteristic responsible for higher yield stability is difficult. According to Duvick et al. (2004), and confirmed by Cooper et al. (2014), the long-term yield gains for maize in the USA could be attributable to the accumulation of multiple traitsand mechanisms - that conferred tolerance to different stresses. As one example, by using a crop model, Hammer et al. (2009) could provide evidence that one trait that had a positive effect on water capture and a direct effect on biomass accumulation was the increase in root density in maize. This corroborates the statement that a well-designed and calibrated model can provide important support for breeding programs (Semenov and Stratonovitch 2013).

The results here demonstrated attend the needs stated done by Soler et al. (2007), for whom the application of the crop modeling process should be done for other locations to 
support practical decisions. The same authors also refer to the importance of the additional model calibration and evaluation for new cultivars, as the ones included in this study.

Finally, climate-proof strategies comprising improved short- and medium-term climate forecasts, so as improved cultivars and efficient rainwater management, are critical for improving rain-fed agriculture (Kassie et al. 2014).

\section{Conclusions}

The cultivars MPA01, Fortuna, and AS1548 were calibrated and validated allowing the DSSAT-CERES-Maize model to mimic the phenology and biomass accumulation of the studied cultivars of maize. One open-pollinated cultivar (Ivanir) could not be calibrated due to its high phenotypic variability, which prevented the proper simulation by the DSSATCERES-Maize model.

Planting dates had a significant impact on maize yield, with the less risky planting window between September and October. In the majority of the situations with reduction in precipitation, amount yields were negatively impacted. The open-pollinated cultivar Fortuna and the hybrid AS1548 reached the highest yields (6127 and $6051 \mathrm{~kg} \mathrm{ha}^{-1}$, respectively). The cultivar MPA01 presented an average yield of $5647 \mathrm{~kg} \mathrm{ha}^{-1}, 8$ and $7 \%$ lower than the AS1548 and Fortuna, respectively. The yields of the tested cultivars corroborate the study region's actual yields, which range from 3689 to $6275 \mathrm{~kg} \mathrm{ha}^{-1}$.

The open-pollinated cultivar MPA01, derived from a participatory breeding program and designed for cultivation in agroecological systems, presented the highest yield stability and lowest probability of crop failure under different scenarios of temperature and precipitation when compared to the hybrid AS1548 and the open-pollinated cultivar Fortuna. The response surfaces indicate that the open-pollinated cultivars Fortuna and MPA01 are a feasible option to cope with negative impacts of climate variability and change in rainfed systems, presenting acceptable yields and a reduced probability of crop failure.

Acknowledgements The activities related to this work were all done with support of the CLARIS LPB Project. The first author expresses his gratitude to the agricultural technician Adriano Canci and the Rockenbach's family for all the support during the field experiment and the UNOESC for the laboratorial structure. The research leading to these results has received funding from the European Community's Seventh Framework Programme (FP7/2007-2013) under Grant Agreement No. 212492: CLARIS LPB - A Europe-South America Network for Climate Change Assessment and Impact Studies in La Plata Basin.

Open Access This article is distributed under the terms of the Creative Commons Attribution 4.0 International License (http:// creativecommons.org/licenses/by/4.0/), which permits unrestricted use, distribution, and reproduction in any medium, provided you give appropriate credit to the original author(s) and the source, provide a link to the Creative Commons license, and indicate if changes were made.

\section{References}

ABRASEM (2006) Anuário Abrasem 2006. Associação brasileira de sementes e mudas, Brasília

Bannayan M, Hoogenboom G (2009) Using pattern recognition for estimating cultivar coefficients of a crop simulation model. F Crop Res 111:290-302. doi:10.1016/j.fcr.2009.01.007

Bellon MR, Adato M, Becerril J, Mindek D (2006) Poor farmers' perceived benefits from different types of maize germplasm: the case of creolization in lowland tropical Mexico. World Dev 34:113-129. doi:10.1016/j.worlddev.2005.05.012

Boote KJ (1999) Data required for model evaluation and techniques for sampling crop growth and development. In: Hoogenboom G, Wilkens PW, Tsuji GY (eds) DSSAT v3. University of Hawaii, Honolulu, pp 201-216

Canci A, Voigt GA, Canci I (2004) A Diversidade das Especies Crioulas em Anchieta-SC: Diagnóstico, Resultado de Pesquisa e Outros Apontamentos para a Conservação da Agrodiversidade. McLee, São Miguel do Oeste

Cooper M, Gho C, Leafgren R et al (2014) Breeding drought-tolerant maize hybrids for the US corn-belt: discovery to product. J Exp Bot 65:6191-6194

Cubasch U, Meehl GA, Boer GJ et al (2001) Projections of future climate change. In: Houghton JT, Ding TY, Griggs DJ et al (eds) Climate change 2001: the scientific basis. Contribution of Working Group I to the Third Assessment Report of the Intergovernmental Panel on Climate Change. Cambridge University Press, Cambridge and New York, pp 525-582

Duvick DN (2005) The contribution of breeding (Zea mays L.) Adv Agron 86:83-145. doi:10.1016/S0065-2113(05)86002-X

Duvick DN, Smith JSC and Cooper M (2003) Long-term selection in a commercial hybrid maize breeding program. In: Plant breeding reviews: long-term selection: crops, animals, and bacteria, vol. 24. Part 2 (ed Janick J), John Wiley \& Sons, Inc., Oxford, UK. doi: 10.1002/9780470650288.ch4

Hall AJ, Richards RA (2013) Prognosis for genetic improvement of yield potential and water-limited yield of major grain crops. F Crop Res 143:18-33. doi:10.1016/j.fcr.2012.05.014

Hammer GL, Dong Z, McLean G et al (2009) Can changes in canopy and/or root system architecture explain historical maize yield trends in the U.S. corn belt? Crop Sci 49:299-312. doi:10.2135/cropsci2008.03.0152

Homaee M, Dirksen C, Feddes RA (2002) Simulation of root water uptake I. Non-uniform transient salinity using different macroscopic reduction functions. Agric Water Manag 57:89109. doi:10.1016/S0378-3774(02)00072-0

IBGE (2015) SIDRA-IBGE: aggregated database. In: Brazilian Inst. Geogr. Stat. http://www.sidra.ibge.gov.br. Accessed 1 May 2016

IPCC (2014) Climate change 2014: synthesis report. Contribution of Working Groups I, II and III to the Fifth Assessment Report of the Intergovernmental Panel on Climate Change

Jamieson PD, Asseng S, Chapman SC et al (2010) Modelling wheat production. In world heat (eds. Bonjean AP, Angus WJ and Ginkel MV), Vol. 2, pp. 783-812.). Paris: Lavoisier

Jones JW, Hoogenboom G, Porter CH et al (2003) The DSSAT cropping system model. Eur J Agron 18:235-265. doi:10.1016/S11610301(02)00107-7

Joshi KD, Khanal NP, Harris D et al (2014) Regulatory reform of seed systems: benefits and impacts from a mungbean case study in Nepal. F Crop Res 158:15-23. doi:10.1016/j.fcr.2013.12.011 
Kassie BT, Van Ittersum MK, Hengsdijk H et al (2014) Climate-induced yield variability and yield gaps of maize (Zea mays L.) in the Central Rift Valley of Ethiopia. F Crop Res 160:41-53. doi:10.1016/j.fcr. 2014.02.010

Kist V, Ogliari JB, Miranda JB, Alves AC (2010) Genetic potential of a maize population from Southern Brazil for the modified convergentdivergent selection scheme. Euphytica 176:25-36. doi:10.1007/ s10681-010-0207-y

Kuhnen S, Ogliari JB, Dias PF et al (2010) ATR-FTIR spectroscopy and chemometric analysis applied to discrimination of landrace maize flours produced in southern Brazil. Int J Food Sci Technol 45:16731681. doi:10.1111/j.1365-2621.2010.02313.x

Kutka F (2011) Open-pollinated vs. hybrid maize cultivars. Sustainability 3:1531-1554

Loague K, Green RE, Loague Keith GRE et al (1991) Statistical and graphical methods for evaluating solute transport models: overview and application. J Contam Hydrol 7:51-73. doi:10.1016/01697722(91)90038-3

Markelz RJ, Strellner RS, Leakey AD (2011) Impairment of C(4) photosynthesis by drought is exacerbated by limiting nitrogen and ameliorated by elevated $[\mathrm{CO}(2)]$ in maize. J Exp Bot 62:3235-3246. doi: $10.1093 / \mathrm{jxb} / \mathrm{err} 056$

Mercer KL, Perales HR (2010) Evolutionary response of landraces to climate change in centers of crop diversity. Evol Appl 3:480-493

Newton AC, Akar T, Baresel JP et al (2010) Cereal landraces for sustainable agriculture. A review. Agron Sustain Dev 30:237-269. doi:10. 1051/agro/2009032

Padilla JM, Otegui ME (2005) Co-ordination between leaf initiation and leaf appearance in field-grown maize (Zea mays): genotypic differences in response of rates to temperature. Ann Bot 96:9971007. doi:10.1093/aob/mci251

Peel MC, Finlayson BL, McMahon TA (2007) Updated world map of the Köppen-Geiger climate classification. Hydrol Earth Syst Sci Discuss 4:439-473

Reidsma P, Ewert F, Lansink AO, Leemans R (2010) Adaptation to climate change and climate variability in European agriculture: the importance of farm level responses. Eur J Agron 32:91-102. doi: 10.1016/j.eja.2009.06.003

Ritchie JT, Singh U, Godwin DC, Bowen WT (1998) Cereal growth, development and yield. In: Tsuji GY, Hoogenboom G, Thornton PK (eds) Understanding options for agricultural production, 7th edn. Kluwer Academic Publishers, Dordrecht, pp 79-98

Semenov MA, Stratonovitch P (2013) Designing high-yielding wheat ideotypes for a changing climate. Food Energy Secur 2:185-196. doi: $10.1002 /$ fes3.34

Soler CMT, Sentelhas PC, Hoogenboom G (2007) Application of the CSM-CERES-maize model for planting date evaluation and yield forecasting for maize grown off-season in a subtropical environment. Eur J Agron 27:165-177. doi:10.1016/j.eja.2007.03.002

Wallach D, Makowski D, Jones JW, Brun F (2014) Chapter 9-model evaluation. In: Wallach D, Makowski D, Jones JW, Brun F (eds) Working with dynamic crop models (second edition), 2nd edn. Academic Press, San Diego, pp 345-406

Zhang S, Sadras V, Chen X, Zhang F (2014) Water use efficiency of dryland maize in the Loess Plateau of China in response to crop management. F Crop Res 163:55-63. doi:10.1016/j.fcr.2014.04.003 